\title{
Astrocyte Development and Heterogeneity
}

\author{
Omer Ali Bayraktar ${ }^{1,2,4}$, Luis C. Fuentealba ${ }^{3,4}$, Arturo Alvarez-Buylla ${ }^{1,3}$, \\ and David H. Rowitch ${ }^{1,2}$ \\ ${ }^{1}$ Department of Pediatrics and Edythe Broad Institute for Stem Cell Research and Regeneration \\ Medicine, University of California, San Francisco, San Francisco, California 94143 \\ ${ }^{2}$ Howard Hughes Medical Institute, University of California, San Francisco, San Francisco, California 94143 \\ ${ }^{3}$ Department of Neurosurgery, Eli and Edythe Broad Institute for Stem Cell Research and Regeneration \\ Medicine, University of California, San Francisco, San Francisco, California 94143 \\ Correspondence: ABuylla@stemcell.ucsf.edu; rowitchd@peds.ucsf.edu
}

\begin{abstract}
Astrocytes have many roles within the brain parenchyma, and a subpopulation restricted to germinal niches functions as neural stem cells (NSCs) that produce various types of neuronal progeny in relation to spatiotemporal factors. A growing body of evidence supports the concept of morphological and molecular differences between astrocytes in different brain regions, which might relate to their derivation from regionally patterned radial glia. Indeed, the notion that astrocytes are molecularly and functionally heterogeneous could help explain how the central nervous system (CNS) retains embryonic positional information into adulthood. Here, we discuss recent evidence for regionally encoded functions of astrocytes in the developing and adult CNS to provide an integrated concept of the origin and possible function of astrocyte heterogeneity. We focus on the regionalization of NSCs in the ventricular-subventricular zone (V-SVZ) of the adult mammalian brain and emerging evidence for a segmental organization of astrocytes in the developing spinal cord and forebrain. We propose that astrocytes' diversity will provide fundamental clues to understand regional brain organization and function.
\end{abstract}

$\mathrm{A}^{\mathrm{l}}$ lthough neurons have long been accepted as a functionally diverse population, astrocytes, the most abundant cell types in the mammalian brain, are regarded as relatively homogeneous and interchangeable. Indeed, many lines of evidence support this view. Electrophysiological properties of astrocytes between central nervous system (CNS) regions are similar and markers for astrocytes are similarly expressed in different brain regions. Astrocyte development has long been considered to be a "default state," commencing when proneural programs extinguish and/or radial glia (RG) mature.

This and other articles in the collection will challenge the notion of astrocyte homogeneity and cover emerging studies that indicate their importance in a variety of neurological functions. For example, once considered passive players that provide structural and metabolic support for neurons, astrocytes are now recognized as potent regulators of synapse formation, subsequent fine-tuning, and maintenance

${ }^{4}$ These authors contributed equally to this work.

Editors: Ben A. Barres, Marc R. Freeman, and Beth Stevens

Additional Perspectives on Glia available at www.cshperspectives.org

Copyright (C) 2015 Cold Spring Harbor Laboratory Press; all rights reserved; doi: 10.1101/cshperspect.a020362

Cite this article as Cold Spring Harb Perspect Biol 2015;7:a020362 
O.A. Bayraktar et al.

(Chung et al. 2013; Clarke and Barres 2013). The genetic mechanisms that underlie astrocyte development have been reviewed recently elsewhere (Rowitch and Kriegstein 2010; Molofsky et al. 2012). The purpose of this review is to cover evidence for spatiotemporal heterogeneity of astroglial populations in the brain and spinal cord. The notion of astrocyte heterogeneity most likely stems from Ramón y Cajal, who noted several distinctive astrocyte morphologies (Parpura and Haydon 2008) that are readily apparent in the human brain (Oberheim et al. 2006). Other studies report differences in astrocyte expression profiles across regions of the CNS (Bachoo et al. 2004; Regan et al. 2007; Doyle et al. 2008; Krencik et al. 2011). However, establishing functional astrocyte heterogeneity represents a major frontier for investigation.

Might positional signals, encoded during the process of embryonic pattern formation, carried forward in a heritable fashion diversify stem cell populations of the ventricular-subventricular zone (V-SVZ), as well as parenchymal astrocytes? Indeed, in the postnatal period, we will argue that astrocytes comprise a key population to encode positional cues and other locally restricted factors that may be required for neuron subtype survival and circuit formation and/or maintenance. We propose that the concept that astrocytes are highly heterogeneous and retain important information will be fundamental to our understanding of the origin of neuronal diversity and to the development and possibly the normal function of brain circuits.

\section{HETEROGENEITY OF NEURAL STEM CELLS (NSCS) OF THE V-SVZ}

\section{Embryonic Patterning Specifies NSC Heterogeneity \\ Regional Heterogeneity of Forebrain NSCs during Embryonic Development}

How are NSCs programmed to produce diversified neural progeny? During embryonic development, RG cells derived from the neuroepithelium are the primary NSCs that produce neurons and glia throughout the brain (Noctor et al. 2002; Anthony et al. 2004; and reviewed in Kriegstein and Alvarez-Buylla 2009). These cells, like their neuroepithelial precursors, contain apicobasal specializations with their cell bodies retained in the ventricular zone (VZ). Although neuroepithelial cells and RG appear to be homogeneous populations of dividing cells lining the ventricles, they are regionally specialized for producing distinct subtypes of neurons (Campbell 2003; Puelles and Rubenstein 2003). These progenitor domains are established by cell-extrinsic positional signals, such as dorsal bone morphogenetic protein (BMP) and ventral Sonic hedgehog (Shh), and are further refined by the expression of numerous transcription factors (Campbell 2003; Sur and Rubenstein 2005). Along the dorsoventral (DV) axis of the forebrain, major RG domains include the pallium (cortex), subpallial structures (lateral and medial ganglionic eminences [LGEs and MGEs, respectively]), and the septum (Fig. 1). Cortical progenitors produce different layers of projection neurons with distinct morphological and functional identities. Conversely, LGE progenitors produce projection neurons of the striatum and olfactory bulb $(\mathrm{OB})$ interneurons, whereas MGE progenitors give rise to the interneurons that populate the different regions of the telencephalon, as well as projection neurons of the pallidum and basal forebrain (Campbell 2003; Wonders and Anderson 2006; Flames et al. 2007). Similar subdivisions are present in the anteroposterior axis of the forebrain (Puelles and Rubenstein 2003; Greig et al. 2013). Regional diversity of forebrain progenitors also underlies development of diversified glial subtypes at later developmental stages of embryogenesis (Rowitch and Kriegstein 2010) as discussed below.

\section{Temporal Heterogeneity of NSCs during Embryonic Development}

Do temporal factors also contribute to neural diversification from forebrain NSCs? Indeed, a number of different studies have shown that the neurogenic potential of RG changes over time (reviewed in Kohwi and Doe 2013). This temporal patterning has been best studied in the developing pallium (cortex) and retina (McConnell 
A

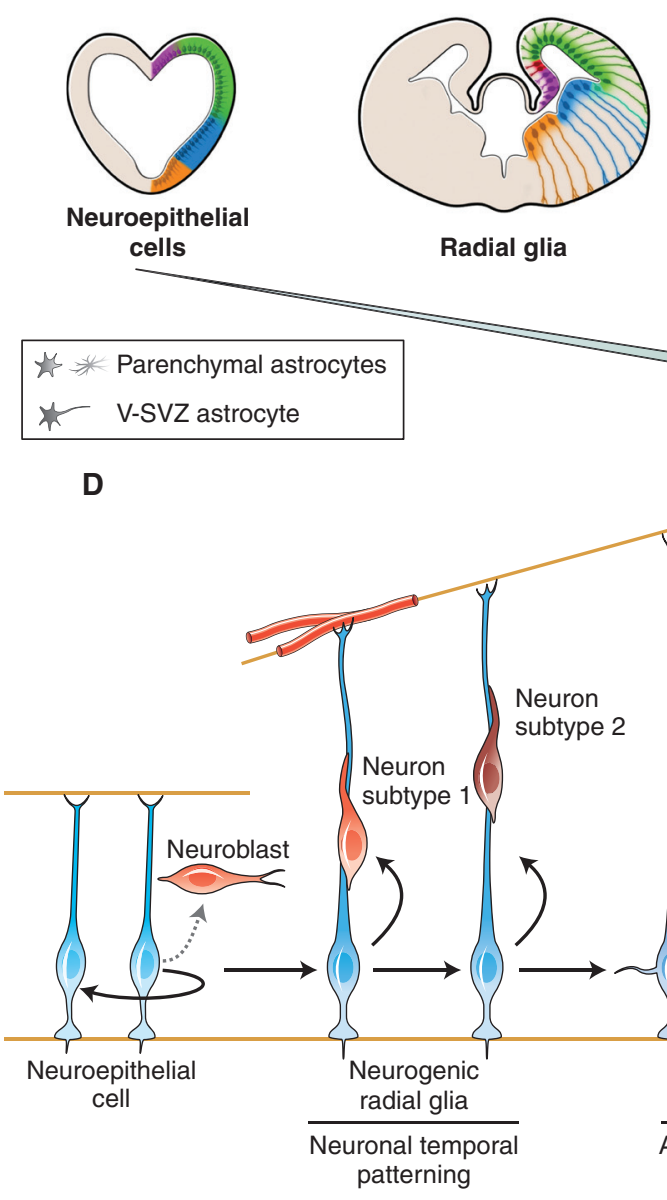

C

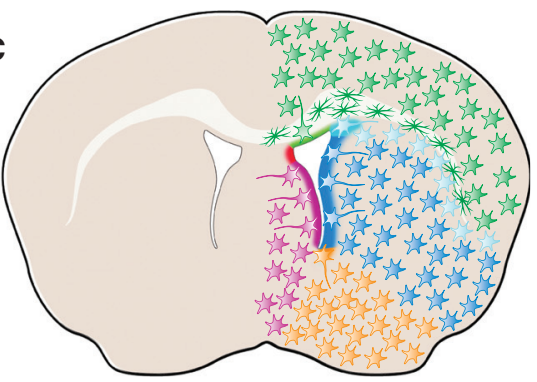

Parenchymal and V-SVZ astrocytes
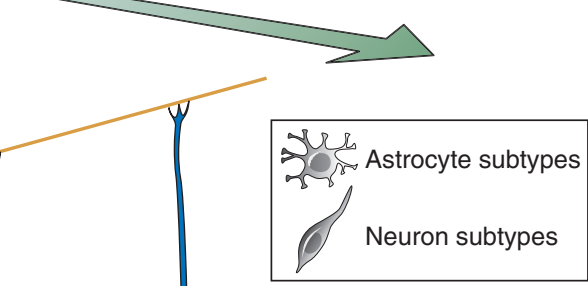

Neuron subtypes

\begin{tabular}{l|l} 
Astrocyte \\
subtype 1 & subtype 2
\end{tabular}

Figure 1. Developmental origins of adult parenchymal and V-SVZ astrocyte heterogeneity. $(A)$ The regional specification of neuroepithelial (NE) cells, $(B)$ radial glia (RG), and $(C)$ V-SVZ and parenchymal astrocytes $(D)$ throughout development. NE and RG cells at different regions of the developing forebrain $(A$ and $B)$, including the pallium (green), the lateral and medial ganglionic eminences (LGE and MGE in blue and orange, respectively), and septum ( purple), give rise to adult V-SVZ NSCs at the different walls of the lateral ventricles and parenchymal astrocytes that maintain key positional information cues to control the progeny they produce and function, respectively. $(D)$ Neural stem cell lineage progression during brain development. NE gives rise to neurogenic RG that generate different neuronal subtypes in a sequential manner. At later stages of embryogenesis, neurogenic RG become gliogenic to produce astrocytes. Whether RG sequentially generate different astrocyte subtypes remains to be determined. The final location of astrocytes in restricted spatial domains is determined by a DV segmental template. RG also give rise to V-SVZ astrocytes that produce different subtypes of OB interneurons depending on the region in which they are located. OB, olfactory bulb; V-SVZ, ventricular-subventricular zone.

1992; Cepko et al. 1996). Cortical neurogenesis begins with the production of deeper projection neurons (E11-E13 in mouse) and continues with successive generation of superficial projection neurons (E14-E16). These periods of neurogenesis are then followed by increased gliogen- esis. Astrocytes are first detected around E16 and oligodendrocytes around birth; however, the vast majority of both cell types are produced during the first month of postnatal development. Remarkably, this timing mechanism appears to rely on cell-intrinsic temporal cues be- 
O.A. Bayraktar et al.

cause it can be recapitulated in clonal culture (Qian et al. 2000; Shen et al. 2006).

An important question that remains to be answered is whether individual RG produce different neural subtypes progressively. Clonal studies with retroviral labeling, or mouse stem cell chimeras, have suggested that this stereotypic sequence of neuronal and glia production may take place within individual progenitors (Walsh and Cepko 1988; Tan et al. 1995; Magavi et al. 2012; Guo et al. 2013; and reviewed in Kriegstein and Alvarez-Buylla 2009). On the other hand, fate-restricted progenitors producing only subtypes of neurons or only glia have also been observed to coexist at early stages of development using retrovirus labeling (Luskin et al. 1988, 1993; Price and Thurlow 1988; Parnavelas et al. 1991; Grove et al. 1993; Parnavelas 1999; McCarthy et al. 2001; Wu et al. 2006). One caveat of these experiments is that retroviruses, which infect dividing cells only, do not distinguish between multipotent or fate-restricted progenitors, such as intermediate progenitors (Kriegstein and Alvarez-Buylla 2009).

Taken together, it is now clear that the embryonic neuroepithelium is composed of a heterogeneous mix of progenitors that produce different neural subtypes within specific spatiotemporal boundaries. The developmental timing and location of RG, a property tightly linked to their neuroepithelial origin, appear to be the key determinants of the types of neurons generated. As we will describe below, similar, if not the same, spatial and temporal patterning programs appear to diversify the neuronal progeny of adult NSCs and, perhaps, parenchymal astrocytes into functional subtypes.

\section{Adult V-SVZ Astrocytes Are Regionally Specified NSCs}

The Neurogenic Nature of Adult V-SVZ Astrocytes Defines Them as NSCs

Are astrocytes in selected regions of the brain NSCs? Throughout postnatal life in rodents and probably many other mammals, relatively quiescent NSCs (or B1 cells) are retained in the VSVZ in the walls of the lateral ventricles. These primary progenitors give rise to rapidly divid- ing intermediate progenitors (also known as $\mathrm{C}$ cells) that produce large numbers of young neurons (or A cells). These immature cells migrate over long distances to reach the $\mathrm{OB}$ where they differentiate into multiple types of local interneurons. These cells become integrated into functional circuits continually replacing older cells in a process that has been suggested to be important for neuronal plasticity and the processing of olfactory information (Cecchi et al. 2001; Petreanu and Alvarez-Buylla 2002; Wachowiak and Shipley 2006; Imayoshi et al. 2008; Lledo et al. 2008; Sakamoto et al. 2014).

Adult B1 cells were originally identified as astrocytes because of the many markers (glial fibrillary acidic protein [GFAP], Glast, and Nestin), morphology, and ultrastructure they share with differentiated astroglial cells (Paterson et al. 1973; Doetsch et al. 1999). The neurogenic properties of these adult V-SVZ astrocytes were shown by a number of different experiments. After treatment with the antimitotic drug, Ara-C, which eliminates fast-dividing C and A cells, only B1 cells and ependymal cells remain in the V-SVZ. B1 cells divide and regenerate the population of transient amplifying $\mathrm{C}$ cells that, in turn, generate neuroblasts to repopulate the whole neurogenic V-SVZ lineage (Doetsch et al. 1999). Specific targeting of GFAP-expressing $\mathrm{B} 1$ cells further corroborated these experiments. Using a reporter-expressing avian leukosis (RCAS) retrovirus that infects cells with a GFAP-promoter-driven Tva receptor-which is required for RCAS internalization-results in the subsequent generation of new neurons that migrated into the $\mathrm{OB}$ (Doetsch et al. 1999; Laywell et al. 2000). Finally, the astrocytic nature of adult progenitors was further established by studies using transgenic mice expressing herpes simplex virus thymidine kinase (HSV-TK) under the control of the GFAP promoter. In these mice, treatment with the antiviral agent ganciclovir results in the specific ablation of GFAP-expressing cells and, consequently, a substantial reduction in the generation of new neurons in vitro and in vivo (Imura et al. 2003; Morshead et al. 2003). Thus, V-SVZ astrocytes function as NSCs in the adult brain. Indeed, several recent studies have suggested 
that astrocytes in parenchyma might also have increased potential to produce neurons in the setting of injury (Sirko et al. 2013), suggesting that NSC properties might be retained under certain circumstances.

\section{Regional Heterogeneity of Adult V-SVZ Astrocytes}

Do adult V-SVZ NSCs retain heterogeneous regional properties? During development, B1 cells are derived from RG (Merkle et al. 2004, 2007). As discussed above, embryonic neuroepithelial cells and RGs are organized into distinct spatial domains. Recent studies using stem cell transplantation and genetic fate-mapping experiments revealed that $\mathrm{B} 1$ cells in the V-SVZ are also heterogeneous. Progenitors located in different regions of the V-SVZ generate specific subtypes of interneurons (Hack et al. 2005; Allen et al. 2007; Kohwi et al. 2007; Young et al. 2007). Thus, it has been proposed that this $\mathrm{V}-\mathrm{SVZ}$ positional identity may be determined by a combination of transcription factors expressed early in development and maintained postnatally (Allen et al. 2007; Merkle et al. 2007; Kriegstein and Alvarez-Buylla 2009). Earlier work suggested that the majority of the adult V-SVZ is derived from the LGE (Wichterle et al. 1999). Consistently, much of the adult V-SVZ shows expression of transcription factors typical of the dorsal LGE, such as Gsx2, Dlx1/2, ER81, Pax6, and Sp8 (Stenman et al. 2003; Parras et al. 2004; Hack et al. 2005; Kohwi et al. 2007; Waclaw et al. 2009). Mice null for some of these LGE transcription factors are deficient in the production of specific subtypes of OB interneurons in adults (reviewed in Alvarez-Buylla et al. 2008). However, transplantation and cre-mediated lineage-tracing experiments suggest that other regions of the embryonic telencephalon outside of the LGE, such as the cortex (pallium) and septum, also contribute to the adult germinal niche (Kohwi et al. 2007; Young et al. 2007; Brill et al. 2009). Although it was found that these different regions contributed with specific populations of progenitors, it remains unknown whether this regional specification in the embryo relates directly to postnatal regionalization.
Direct evidence for mosaic organization of the postnatal V-SVZ derives from studies that labeled NSCs in discrete locations of the periventricular germinal niche using adenovirus expressing cre (Ad:Cre) injected into mice carrying a conditional reporter (Merkle et al. 2007; Ventura and Goldman 2007). These studies revealed that different types of $\mathrm{OB}$ interneurons are derived from unique locations of the V-SVZ. For instance, dorsal V-SVZ NSCs generate mostly superficial granule cells (GCs) and dopaminergic periglomerular cells (PGCs), whereas ventral NSCs produce deep GCs and calbindin ${ }^{+}$PGCs. Superficial GCs can be subdivided according to calretinin (CalR) expression. Although labeled primary progenitors in the dorsal part of the lateral ventricular wall generated many superficial GCs, very few of these cells expressed CalR. However, targeting NSCs in the anteromedial wall facing the septum labeled many superficial $\mathrm{CalR}^{+}$GCs. CalR ${ }^{+}$PGCs also appear to be derived from this germinal zone, suggesting that a very small subdomain of the V-SVZ in the anteroventral septum produces most of the $\mathrm{CalR}^{+}$ $\mathrm{OB}$ interneurons. Interestingly, this parcellation observed in the V-SVZ region seems to be highly complex. A recent study showed that the anteroventral region of the $\mathrm{V}-\mathrm{SVZ}$, which covers only $5 \%$ of the total surface area, could be further subdivided into smaller microdomains. Surprisingly, these microdomains are finely patterned by a combination of transcription factors (TFs), including Zicl/2/3 and Nkx6.2, to produce at least four previously unknown OB interneuron subtypes (Merkle et al. 2013).

How is the regional heterogeneity of $\mathrm{V}$ SVZ determined? Such positional specification appears to be primarily through a cell-autonomous mechanism, because postnatal green fluorescent protein (GFP)-labeled progenitors transplanted into heterologous locations of the postnatal SVZ maintained their original phenotype (Merkle et al. 2007). Although these experiments strongly suggest that relocation within the V-SVZ is not sufficient to switch stem cell identity, a recent study suggests that a gradient of Shh signaling may determine DV differences in NSC behavior in the postnatal V-SVZ. Interestingly, ectopic dorsal activation of Shh signaling, 
O.A. Bayraktar et al.

by introduction of a constitutively active receptor (SmoM2), is sufficient to make dorsal primary progenitors behave like ventral ones (Ihrie et al. 2011). It will be interesting to determine whether other molecular mechanisms involved in early regional specification, such as Shh, remain operational as a mechanism for plasticity in the adult.

Taken together, V-SVZ astrocytes are regionally heterogeneous; their identity appears to be encoded during development and maintained throughout adulthood. The mosaic organization of the adult V-SVZ provides a powerful system to uncover molecular mechanisms underlying regionalization and cell-fate specification and to understand how early positional codes are retained throughout the entire life of an animal.

\section{Temporal Specification of Adult V-SVZ Astrocytes \\ The NSC Glial Lineage}

In addition to the intricate spatial patterning of V-SVZ astrocytes, temporal mechanisms also appear to regulate adult NSCs. Several observations have led to the proposition that NSCs are contained within the neuroepithelial (NE)RG-B1 cell lineages (Fig. 1) (Alvarez-Buylla et al. 2001). As discussed previously, lineage-tracing experiments have shown that RG give rise to $\mathrm{B} 1$ cells (Merkle et al. 2004, 2007). Similar to their RG predecessors, B1 cells retain key neuroepithelial characteristics, including RG marker expression (such as Nestin, brain lipid-binding protein $[\mathrm{BLBP}]$, and Sox2) and apicobasal polarity with an apical compartment, containing a primary cilium, which contacts the lateral ventricle and a long basal process ending on blood vessels (Mirzadeh et al. 2008; Shen et al. 2008; Tavazoie et al.2008). These features allow B1 cells to interact with multiple environments within their niche and contribute to their neurogenic behavior (reviewed in Fuentealba et al. 2012). Thus, adult NSCs may be derived sequentially from RG progenitors that, earlier in development, produce the different neuronal subpopulations of the forebrain (Alvarez-Buylla et al.
2001; Kriegstein and Alvarez-Buylla 2009). A recent study using time-lapse clonal analysis in vitro showed that individual E11.5 cortical progenitors could generate $\mathrm{Tbr} 1^{+}$projection neurons followed by $\mathrm{GAD} 7^{+} / \mathrm{SP} 8^{+} \mathrm{OB}$ interneurons. These observations suggest that individual embryonic cortical progenitors may contribute sequentially to projection neurons and, at later time points, OB interneurons (Cai et al. 2013).

Remarkably, these timing mechanisms may work in concert with spatial transcriptional programs described previously. A recent study showed that conditional genetic manipulation of the LGE TF, Gsx2, results in time-dependent distinctive cell fate changes in the developing telencephalon. Gsx2 is required for both striatal (early) and $\mathrm{OB}$ (late) neuronal generation. Early (E9.5) misexpression of Gsx2 results in the respecification of the developing forebrain into an Isl1-expressing striatal cell phenotype, whereas late (E13.5) Gsx2 missexpression promoted $\mathrm{SP}^{+} \mathrm{OB}$ specification. Conversely, conditional inactivation of Gsx2 at midneurogenesis only affects $\mathrm{OB}$ but not striatal neuronal identity (Waclaw et al. 2009). These results differ from germline deletion of Gsx2, which results in aberrant generation of both striatal and $\mathrm{OB}$ neuronal subtypes (Corbin et al. 2000; Yun et al. 2003; Waclaw et al. 2009). Similar temporal mechanisms of cell fate specification switch may take place in the different regions of the developing telencephalon.

\section{Temporal Patterning of Adult V-SVZ NSCs}

It is unclear whether progeny subtypes derived from V-SVZ NSCs change in a temporal manner, analogous to what has been observed with cortical and retinal progenitors. Stem cell transplantation experiments suggest that neonatal and adult progenitors produce different proportions of PGCs. Neonatal progenitors give rise preferentially to $\mathrm{CalB}^{+}$PGCs, whereas adult progenitors produce higher numbers of $\mathrm{CalR}^{+}$ and $\mathrm{TH}^{+}$PGCs (De Marchis et al. 2007). In a separate study, fate mapping of $\mathrm{OB}$ progenitors using an inducible genetic method also showed that the neuronal progeny identity varied between progenitors at different developmental 
stages (Batista-Brito et al. 2008). Similar to the study by De Marchis et al., late embryonic and neonatal NSCs produced progeny that preferentially expressed $\mathrm{CalB}^{+}$PGCs, whereas adult NSC progeny contributed mostly CalR ${ }^{+}$PGCs. However, it was found that $\mathrm{TH}^{+} \mathrm{PGC}$ production is highest at early developmental stages and decreases after birth (Batista-Brito et al. 2008). Interestingly, the ratio of these three subpopulations of interneurons, $\mathrm{CalB}^{+}, \mathrm{CalR}^{+}$, and $\mathrm{TH}^{+}$ PGCs, does not appear to change from neonatal to adult stages, suggesting that the production of these OB subtypes is tightly linked to their turnover in the OB neuronal circuitry (Kohwi et al. 2007). This raises the possibility that activity-dependent survival mechanisms might feed back to regulate progeny cell production through as-yet undetermined mechanisms.

In summary, RG and a subpopulation of astrocytes in the V-SVZ region are regionally and temporally specified to generate a wide variety of neuronal and glial subpopulations. Regional specification may allow the preservation of relative positional information as NSCs transform from neuroepithelial cells to RG and to adult progenitor astrocytes. In parallel, temporal factors may dictate the order and subtype of neuron (and/or glia) that NSCs produce within these individual domains. It will be interesting to determine how the dynamic molecular mechanisms for primary progenitor specification are maintained during the progression of the NERG-B1 cell lineage. Whether these mechanisms take place in individual progenitors is an important question that remains to be determined.

\section{HETEROGENEITY OF MAMMALIAN ASTROCYTES}

\section{Mammalian Astrocytes: A Functionally Diverse Population?}

The previous section shows how both embryonic and adult NSCs are spatiotemporally patterned to specify neuronal heterogeneity. As neurogenesis ceases, NSCs switch to glial production and generate a vast number of parenchymal astrocytes. These mature astrocytes have an extensive repertoire of functions in the mam- malian CNS. An emerging question is whether this wide spectrum of roles is (1) shared by all astrocytes, (2) divided between functionally heterogeneous astrocyte subtypes intermixed in all CNS domains, or (3) segregated to regional astrocyte domains with specialized local functions in neuronal circuit support. One approach is to ask whether mature astrocytes acquire regional and/or temporal functional differences like embryonic RG and adult V-SVZ astrocytes throughout development. Here, we focus on brain and spinal cord development leading to the diversification of astrocytes. Unlike diversification of adult V-SVZ NSCs, however, the literature on heterogeneity of astrocytes is relatively small and functional astrocyte diversity is an emerging concept.

\section{Morphological and Molecular Heterogeneity of Parenchymal Astrocytes}

Several lines of evidence indicate that astrocytes are a heterogeneous population of cells. Morphologically, two broad astrocyte subtypes have long been recognized. Fibrous astrocytes that populate the white matter have a "starlike" appearance with regular contours, whereas protoplasmic astrocytes that populate the gray matter have more irregular "bushy" processes. More recent studies have revealed further details of the astrocyte expression profile (Cahoy et al. 2008; Yang et al. 2011) and how this can vary across broad CNS regions (e.g., cerebellar vs. cortical astrocytes) (Bachoo et al. 2004; Regan et al. 2007; Doyle et al. 2008; Krencik et al. 2011), indicating molecular heterogeneity. However, the functional correlates of these morphological and molecular subtypes have not been clearly shown. Culture and transplantation experiments have identified functional differences among astrocytes from different brain regions (Denis-Donini et al. 1984; Petit et al. 2001), yet these observations have not been confirmed by the manipulation of respective astrocyte subtypes in vivo. In particular, it has been challenging to manipulate astrocyte function in a celltype and region-specific manner. Moreover, some known astrocyte functions are hard to measure in vivo (e.g., nutrient delivery). We 
O.A. Bayraktar et al.

have covered elsewhere that new molecular markers and genetic tools allowing specific manipulation of astrocyte subpopulations are required for dissecting astrocyte heterogeneity (Molofsky et al. 2012). In addition, invertebrate model systems could play an important role in exploring novel astrocyte functions (Freeman and Rowitch 2013).

\section{A Spatial/Segmental Template Underlies} Astrogenesis and Regional Allocation

During development, spatiotemporal patterning programs similar to those discussed above for neurons might also specify diverse astrocyte subtypes from gliogenic progenitors. If so, astrocytes with distinct spatiotemporal origins in the CNS could be functionally heterogeneous. The following sections review progress over the past decade that examine segmental origins of developing astrocytes with a view to their potential functional diversification.

\section{Embryonic Pattern Formation in the Spinal Cord}

Does neural tube patterning regulate astrocyte subtype identity? Early in embryogenesis, gradients of cell-extrinsic organizing signals, such as ventral Shh and dorsal BMPs, lead to the segmentation of the neuroepithelium into discrete DV-restricted progenitor domains (Jessell 2000). This is reflected in the segmental expression of homeodomain and basic helixloop-helix (bHLH) transcription factors that subsequently engage in cross-repressive interactions to refine domain boundaries (e.g., p0, p1, $\mathrm{p} 2$, and $\mathrm{p} 3$ domains) that generate interneuron subtypes, and a pMN domain that generates motor neurons. Thus, spatial patterning in the spinal cord confers positional identity to neural progenitors and creates a segmental template that underlies neuronal diversity (see Fig. 2A).

After early embryonic neurogenesis, neural tube progenitor domains switch to glial production (at $\sim 12.5$ days post coitum (dpc) in mouse). Is astrocyte development in the spinal cord based on a segmental template? The genetic studies of bHLH and homedomain tran- scription factors suggested that astrocytes are specified from their progenitors in a positiondependent manner. First, the expression of stem cell leukemia (SCL), encoding a bHLH protein, is restricted to the ventral p2 domain where it promotes the generation of astrocytes and represses Olig2 and oligodendrocyte production (Muroyama et al. 2005). The combinatorial expression of homeodomain proteins Pax6 and Nkx6.1 also distinguish the p1, p2, and p3 domains (Hochstim et al. 2008). This homeodomain code specifies three molecularly heterogeneous astrocyte subpopulations in the white matter (termed VA1-3) identified by the expression of axon and neuronal migration factors Slit 1 and Reelin. Furthermore, the DVarrangement of VA1 -3 astrocytes mirrors the progenitors in the p1-3 domains.

\section{Regional Astrocyte Allocation from a Segmental Progenitor Template}

The studies above provided an initial indication that astrocytes are specified according to a segmental template in the ventral spinal cord. What about the rest of the DV axis of spinal cord and the brain? Addressing this question required methodology to trace astrocytes with distinct segmental origins throughout the CNS. The identification of the astroglial lineagespecific markers Aldh1L1 and AldoC (Cahoy et al. 2008) facilitated such characterization. Aldh1L1-GFP ${ }^{+}$gliogenic RG align along the VZ and extend their processes toward the pial surface at E13.5 (Fig. 2A) and later give rise to transitamplifying cells termed intermediate astrocyte precursors (IAPs) that undergo local proliferation in parenchyma to expand pools of fibrous and protoplasmic astrocytes (Tien et al. 2012); local/proliferating IAPs are also found in the forebrain (Ge et al. 2012). The RGs and IAPs in the ventral domains of the spinal cord start generating astrocytes earlier than their dorsal counterparts, further indicating that astrocytes develop in a segment-specific manner.

How do the astrocytes, derived from distinct segmental RG domains, distribute into the spinal cord white and gray matter? One could imagine that astrocytes could disperse in mul- 


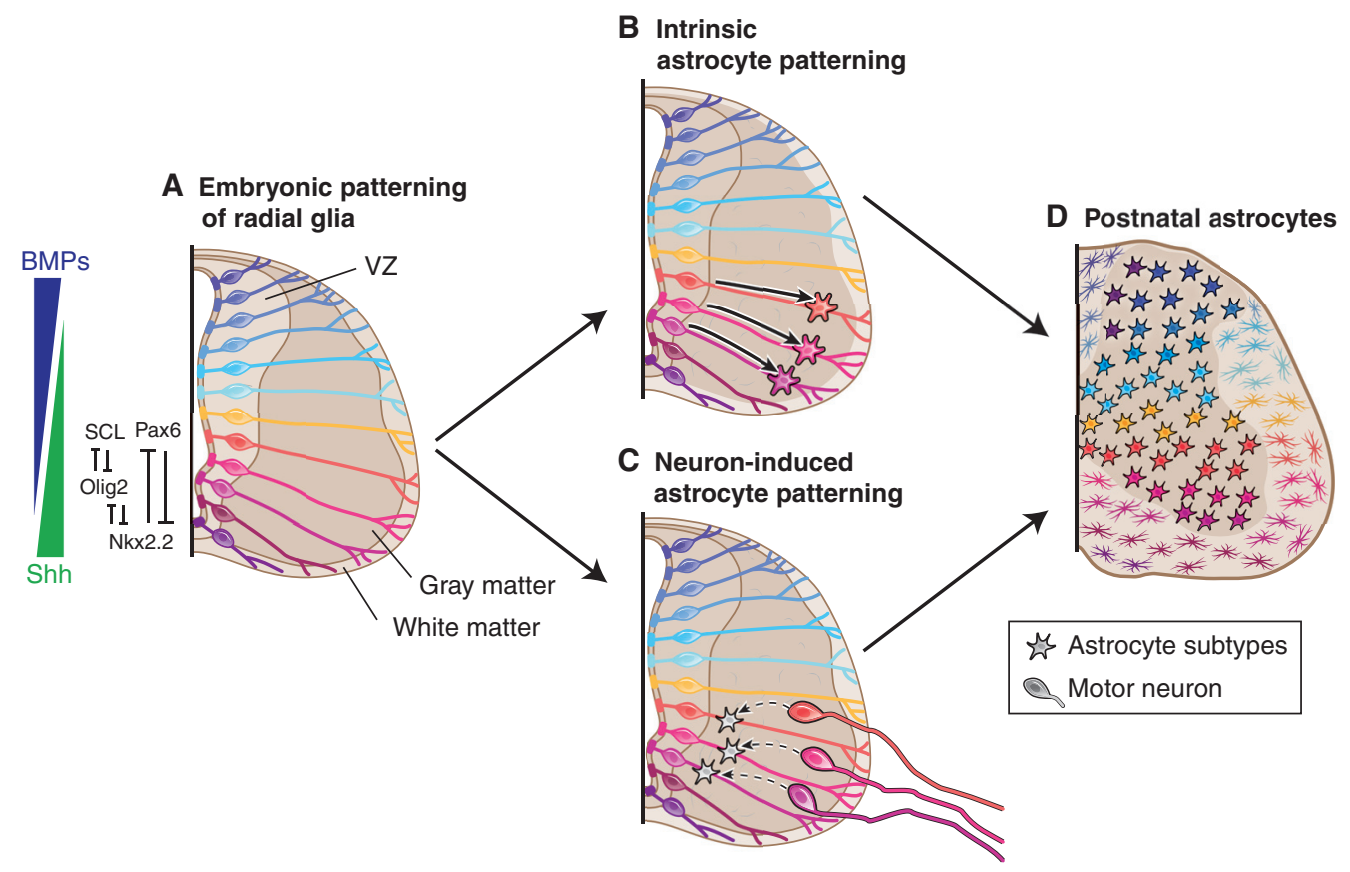

Figure 2. Models of intrinsic versus neuron-induced specification of regional astrocyte heterogeneity in the spinal cord. (A) Embryonic patterning along the DV axis gives rise to regionally specified RG. Signaling by Shh and BMPs regulate the expression of segmental transcription factors, and cross-repressive interactions refine progenitor domains. After neurogenesis, astrocytes are generated in all domains of the spinal cord. They migrate laterally along the RG trajectories and do not undergo tangential migration from their domains of origin. (B) Embryonic patterning specifies regionally distinct astrocytes. The segmental code established during early patterning could be used during gliogenesis to specify segmental astrocyte subtypes and determines the spatial allocation of astrocytes. $(C)$ Extrinsic cues from local neurons might also determine regional astrocyte features (motor neurons are depicted). (D) Segmental heterogeneity of fibrous and protoplasmic astrocytes could give rise to astromeres (i.e., astrocyte domains with distinct functions). This is a speculative concept and an area for future research. BMP, bone morphogenetic protein; SCL, stem cell leukemia; VZ, ventricular zone.

timodal fashion (like oligodendrocyte precursors) to intermix throughout the spinal cord. Alternatively, they might migrate in restricted segmental fashion that would retain spatial coherence with their domains of origin. To investigate this, we performed lineage tracing of $\mathrm{RG}$ and their astrocyte progeny in distinct DV progenitor domains using various regionally expressed cre recombinase lines. These experiments showed that astrocytes maintain a strictly segmental distribution through lateral migration along RG trajectories (Tsai et al. 2012). Astrocytes did not exhibit secondary tangential migration from their domains of origin even after injury or ablation of astrocytes in adjacent domains by diphtheria toxin A (DTA). Thus, astrocytes are regionally allocated into the spinal cord according to a segmental template (Fig. 2) (Tsai et al. 2012).

Is regional allocation of astrocytes a general phenomenon in the CNS? Lineage tracing of RG domains in the forebrain also showed that astrocytes are invested in a region-restricted manner from their domains of origin (Tsai et al. 2012). Clonal labeling of small forebrain RG populations by focal Ad:Cre injections of the cortical, lateral, and medial surfaces of conditional reporter mice (Tsai et al. 2012) or crerecombinase lines that sparsely express in the cortex (Magavi et al. 2012) confirmed this finding, demonstrating that astrocytes become distributed along the territories originally occu- 
O.A. Bayraktar et al.

pied by RG long basal processes (Fig. 1B,C). These results indicate that in contrast to highly migratory oligodendrocytes and many neurons, astrocytes are the least migratory neuroepithelial derivative in the CNS.

Toward a Comprehensive Understanding of Astrocyte Development and Heterogeneity

\section{Regional Astrocyte Functions Regulate the} Sensorimotor Circuit

Might the regional origins and investment of astrocytes couple to their diversification for locally restricted CNS functions? To investigate potential functional astrocyte heterogeneity in the spinal cord, we asked whether astrocytes with dorsal or ventral origins have distinct roles in the maintenance of the sensorimotor circuit. Indeed, previous work revealed that the genetic ablation of ventral astrocytes derived from the pMN domain perturbs specific synaptic inputs into motor neurons (Tsai et al. 2012). To elucidate such regional roles, we used the Aldh1L1GFP reporter to purify dorsal and ventral astrocytes from postnatal day 7 spinal cords by flow cytometry and performed gene expression profiling. These experiments revealed that dorsal and ventral astrocytes differentially express several genes encoding extracellular matrix components or axon and cell migration factors in the CNS, suggesting that regional astrocyte subtypes might encode positional functions during development (Molofsky et al. 2014).

Among regionally expressed astrocyte genes, Semaphorin 3a (Sema3a) was highly enriched in ventral astrocytes. Sema3a is a secreted molecule that acts as a repulsive cue during axon guidance, affects dendrite orientation in the cerebral cortex and hippocampus (Pasterkamp and Giger 2009), and may have other trophic roles. We conditionally removed Sema3a from astrocytes using hGFAP-cre or Aldh1L1-cre. In the wild-type spinal cord, two types of motor neurons, called $\alpha$ and $\gamma$, reside in the ventral gray matter and project axons through the ventral root to their muscle targets. On loss of astrocyte-encoded Sema3a, $\alpha$-motor neurons showed selective loss by P28. Longitudinal analysis in such mutant animals showed abnormalities in motor neuron axon initial segment (AIS) orientation after P0, but not embryonic stages, and astrocyte-encoded Sema3a also was required for normal synaptic motor neuron input/electrophysiology (Molofsky et al. 2014). These results indicate that ventral astrocyte-derived Sema3a is required for the maintenance, but not specification, of motor neuron axon orientation, synaptogenesis, and $\alpha$-motor neuron survival. Although projections of type 1a proprioceptive sensory afferents that synapse onto motor neurons were not affected, we observed ectopic ventral projections of $\operatorname{TrkA}^{+}$sensory axons, indicating that astrocyte-encoded Sema3a also repels sensory axons in vivo, as previously proposed (Kolodkin et al. 1997). Taken together, these findings show that ventral astrocytes play important roles in the maintenance and/or specification of motor neuron and $\operatorname{TrkA}^{+}$sensory axons, $\alpha$-motor neuron survival and function in the sensorimotor circuit, and show the molecular functions of a region-specific astrocyte subtype (Molofsky et al. 2014).

\section{Regional Diversification into Functional "Astromeres"?}

Based on the regional investment of astrocytes in the CNS (Tsai et al. 2012) and our initial studies above, we speculate that regional heterogeneity of astrocytes could be a general phenomenon that gives rise to "astromeres," comprising regionally specialized astrocytes tailored for support of local neuronal subtypes. As exemplified above, astrocytes could help establish neuronal circuits by providing positional guidance cues for migrating neurons and axon path finding. This is supported by studies on midline glial populations during cortical development; these specialized $\mathrm{GFAP}^{+}$cells express several guidance molecules that regulate callosal axon targeting (Shu and Richards 2001; Shu et al. 2003; Unni et al. 2012), suggesting that regionrestricted astrocytes express positional cues across the developing CNS.

During later stages of circuit development, regional astrocytes might support local neurons in synapse formation and pruning. Importantly, 
as astrocytes are generated after the initial specification of neuronal circuitry by embryonic patterning, they could be involved in maintaining neuronal wiring and/or plasticity throughout postnatal development and adult life, perhaps by persistently expressing axon guidance molecules (Koeberle and Bähr 2004). Beyond maintenance, astrocytes could regulate neuronal activity and survival. Our findings in the sensorimotor system indicate that local astrocytes are an integral component of this circuit (Tsai et al. 2012; Molofsky et al. 2014). Thus, it is important to consider the roles of local astrocytes in neural circuit development and function. As illustrated above, molecular profiling of astrocyte subpopulations will be useful for elucidating regionally patterned astrocyte roles. Importantly, given that embryonic patterning could specify regional heterogeneity, the molecular profiling of astrocytes with distinct segmental origins could identify functionally relevant molecular differences. This approach could dissect functional astrocyte subtypes within a CNS region. These studies will rely on new and existing astrocyte-specific genetic tools, such as Aldh1L1-GFP reporter and cre recombinase (Cahoy et al. 2008; Tien et al. 2012). Finally, a better understanding of how astrocytes are patterned during development will help define the extent of astrocyte heterogeneity (see below).

\section{Regulation of Regional Astrocyte Heterogeneity}

How might regional astrocyte subtypes become determined? Spatial astrocyte heterogeneity could be specified by cell-intrinsic and/or cellextrinsic mechanisms. As described above, during pattern formation, cell-intrinsic specification of diverse astrocytes could take place (Fig. $2 \mathrm{~B})$. In this respect, DV patterning mechanisms could collaborate with general proglial transcription factors, such as Sox9 and nuclear factor I/A (NFIA)/B (Rowitch and Kriegstein 2010). Alternatively, diversified neurons might induce diverse properties of astrocytes via cellextrinsic cues (Fig. 2C). Indeed, previous studies have shown that neuron-derived signals could regulate astrocyte development and physiology
(Swanson et al. 1997; Barnabé-Heider et al. 2005; Kaneko et al. 2010); such patterning cues might also be neuronal activity dependent. However, it is important to consider that this neuronal template will not exactly mirror the embryonic segmental pattern, as it will consist of both locally invested and migrating neurons in the CNS. Further investigation is needed to determine whether intrinsic and extrinsic cues act in a combinatorial fashion to determine spatial astrocyte heterogeneity. For example, embryonic patterning could establish certain aspects of regional astrocyte identity, and these properties could be refined by neuronal-derived cues later during development.

A better understanding of regional astrocyte heterogeneity will also require determining whether and how individual astrocyte progenitors become lineage restricted. Previous studies that fate-mapped cortical V-SVZ progenitors with retroviral vectors (Grove et al. 1993; Luskin and McDermott 1994; Parnavelas 1999), or combinatorial expression of fluorescent proteins (Garcia-Marques and Lopez-Mascaraque 2013) showed that protoplasmic and fibrous astrocytes are generated from distinct lineages. Although the mechanisms that define glial progenitor fate potentials are not clear, these observations suggest that distinct astrocyte progenitors within one spatial domain might give rise to diverse astrocyte subtypes and expand regional heterogeneity.

\section{Temporal Heterogeneity of Astrocytes?}

A final speculative concept is the temporal regulation of astrocyte features that could confer additional specialization to parenchymal astrocytes, analogous to that described above for NSCs. Indeed, elegant studies in the Drosophila CNS have shown that individual NSCs could change over time to generate distinct neural subtypes (Kohwi and Doe 2013); these temporal neural identities are specified by sequentially expressed transcription factors in neural progenitors (Isshiki et al. 2001; Bayraktar and Doe 2013; Li et al. 2013). In a similar fashion, vertebrate parenchymal astrocytes could be specified based on their birth time in the CNS or their 
O.A. Bayraktar et al.

birth order from glial progenitors (Fig. 1D). Importantly, temporal patterning cues could be integrated with the spatial determinants of astrocyte heterogeneity to expand the diversity of astrocyte subtypes within each CNS region.

Currently, little is known about vertebrate astrocyte temporal heterogeneity. Early studies noted that protoplasmic and fibrous astrocytes are generated at different times during rat optic nerve development (Miller and Raff 1984). In the mouse spinal cord, astrocytes are generated progressively in a temporal ventral-to-dorsal fashion (Tien et al. 2012), suggesting that segmentally generated astrocytes are also temporally distinct. Future studies can use conditional fate mapping (e.g., Aldh1L1-CreER) and subsequent molecular profiling, or clonal labeling techniques, such as mosaic analysis with double markers (MADM) (Zong et al. 2005) to dissect the temporal heterogeneity of astrocyte progenitors. Alternatively, identification of temporally expressed genes in astrocyte precursors and further utilization of their relevant cis-acting DNA regulatory sequences in fate-mapping experiments could distinguish temporal astrocyte subtypes. It will also be essential to better characterize progenitor types and their proliferation patterns in astrocyte lineages. The transitamplifying intermediate astrocyte precursors observed in the spinal cord and possibly the cerebral cortex (Ge et al. 2012; Tien et al. 2012) could potentially undergo temporal patterning to expand astrocyte heterogeneity in the CNS (Bayraktar and Doe 2013). Finally, it will also be important to consider that some astrocyte functions also change over time. For example, astrocytes secrete thrombospondins 1 and 2, which regulate synaptogenesis largely during postnatal stages but not throughout adulthood (Christopherson et al. 2005).

\section{CONCLUSION}

The idea that astrocytes comprise more than just "glue" (glia) and carry out critical functions in the CNS beyond passive support has been raised repeatedly over the last century. Many new functions have been discovered for astrocytes, some of which are evolutionarily con- served (Freeman and Rowitch 2013). Here, we have described studies showing how astroglial NSCs and parenchymal astrocytes are much more heterogeneous than previously suspected. Important questions outnumber the answers. How is astrocyte heterogeneity generated, and aside from spatial restriction, what is the functional significance? The advent of new genetic tools to purify and genetically modify astrocytes of populations in the developing and mature CNS will be critical to further investigation. In addition, transplantation studies should help determine how plastic regionally specified astrocytes are and whether their local identity is cell autonomously determined. Such studies should provide exciting avenues for the future and may create a new paradigm for thinking about precise cell-cell interactions in regional neural circuit formation and function.

\section{ACKNOWLEDGMENTS}

We are grateful to Hui-Hsin Tsai for comments on the manuscript. L.C.F. acknowledges support from the Howard Hughes Medical Institute (HHMI) and the Helen Hay Whitney Foundation. Studies in our laboratories are supported by Grants from the National Institutes of Health (NIH) HD032116 and NS28478 (to A.A.-B.) and NS059893 (to D.H.R.). A.A.-B. is a Heather and Melanie Muss Endowed Chair. D.H.R. is an HHMI Investigator.

\section{REFERENCES}

Allen ZJ II, Waclaw RR, Colbert MC, Campbell K. 2007. Molecular identity of olfactory bulb interneurons: Transcriptional codes of periglomerular neuron subtypes. $J$ Mol Histol 38: 517-525.

Alvarez-Buylla A, García-Verdugo JM, Tramontin AD. 2001. A unified hypothesis on the lineage of neural stem cells. Nat Rev Neurosci 2: 287-293.

Alvarez-Buylla A, Kohwi M, Nguyen TM, Merkle FT. 2008. The heterogeneity of adult neural stem cells and the emerging complexity of their niche. Cold Spring Harb Symp Quant Biol 73: 357-365.

Anthony TE, Klein C, Fishell G, Heintz N. 2004. Radial glia serve as neuronal progenitors in all regions of the central nervous system. Neuron 41: 881-890.

Bachoo RM, Kim RS, Ligon KL, Maher EA, Brennan C, Billings N, Chan S, Li C, Rowitch DH, Wong WH, et al. 2004. Molecular diversity of astrocytes with implications 
for neurological disorders. Proc Natl Acad Sci 101: 83848389.

Barnabé-Heider F, Wasylnka JA, Fernandes KJ, Porsche C, Sendtner M, Kaplan DR, Miller FD. 2005. Evidence that embryonic neurons regulate the onset of cortical gliogenesis via cardiotrophin-1. Neuron 48: 253-265.

Batista-Brito R, Close J, Machold R, Fishell G. 2008. The distinct temporal origins of olfactory bulb interneuron subtypes. J Neurosci 28: 3966-3975.

Bayraktar OA, Doe CQ. 2013. Combinatorial temporal patterning in progenitors expands neural diversity. Nature 498: 449-455.

Brill MS, Ninkovic J, Winpenny E, Hodge RD, Ozen I, Yang R, Lepier A, Gascon S, Erdelyi F, Szabo G, et al. 2009. Adult generation of glutamatergic olfactory bulb interneurons. Nat Neurosci 12: 1524-1533.

Cahoy JD, Emery B, Kaushal A, Foo LC, Zamanian JL, Christopherson KS, Xing Y, Lubischer JL, Krieg PA, Krupenko SA, et al. 2008. A transcriptome database for astrocytes, neurons, and oligodendrocytes: A new resource for understanding brain development and function. $J$ Neurosci 28: 264-278.

Cai Y, Zhang Y, Shen Q, Rubenstein JL, Yang Z. 2013. A subpopulation of individual neural progenitors in the mammalian dorsal pallium generates both projection neurons and interneurons in vitro. Stem Cells 31: 1193-1201.

Campbell K. 2003. Dorsal-ventral patterning in the mammalian telencephalon. Curr Opin Neurobiol 13: 50-56.

Cecchi GA, Petreanu LT, Alvarez-Buylla A, Magnasco MO. 2001. Unsupervised learning and adaptation in a model of adult neurogenesis. J Comput Neurosci 11: 175-182.

Cepko CL, Austin CP, Yang X, Alexiades M, Ezzeddine D. 1996. Cell fate determination in the vertebrate retina. Proc Natl Acad Sci 93: 589-595.

Christopherson KS, Ullian EM, Stokes CC, Mullowney CE, Hell JW, Agah A, Lawler J, Mosher DF, Bornstein P, Barres BA. 2005. Thrombospondins are astrocyte-secreted proteins that promote CNS synaptogenesis. Cell 120: 421-433.

Chung WS, Clarke LE, Wang GX, Stafford BK, Sher A, Chakraborty C, Joung J, Foo LC, Thompson A, Chen C, et al. 2013. Astrocytes mediate synapse elimination through MEGF10 and MERTK pathways. Nature 504: 394-400.

Clarke LE, Barres BA. 2013. Emerging roles of astrocytes in neural circuit development. Nat Rev Neurosci 14: $311-$ 321.

Corbin JG, Gaiano N, Machold RP, Langston A, Fishell G. 2000. The Gsh2 homodomain gene controls multiple aspects of telencephalic development. Development 127: 5007-5020.

De Marchis S, Bovetti S, Carletti B, Hsieh YC, Garzotto D, Peretto P, Fasolo A, Puche AC, Rossi F. 2007. Generation of distinct types of periglomerular olfactory bulb interneurons during development and in adult mice: Implication for intrinsic properties of the subventricular zone progenitor population. J Neurosci 27: 657-664.

Denis-Donini S, Glowinski J, Prochiantz A. 1984. Glial heterogeneity may define the three-dimensional shape of mouse mesencephalic dopaminergic neurones. Nature 307: 641-643.
Doetsch F, Caillé I, Lim DA, García-Verdugo JM, AlvarezBuylla A. 1999. Subventricular zone astrocytes are neural stem cells in the adult mammalian brain. Cell 97: $703-$ 716.

Doyle JP, Dougherty JD, Heiman M, Schmidt EF, Stevens TR, Ma G, Bupp S, Shrestha P, Shah RD, Doughty ML, et al. 2008. Application of a translational profiling approach for the comparative analysis of CNS cell types. Cell 135: $749-762$.

Flames N, Pla R, Gelman DM, Rubenstein JL, Puelles L, Marín O. 2007. Delineation of multiple subpallial progenitor domains by the combinatorial expression of transcriptional codes. J Neurosci 27: 9682-9695.

Freeman MR, Rowitch DH. 2013. Evolving concepts of gliogenesis: A look way back and ahead to the next 25 years. Neuron 80: 613-623.

Fuentealba LC, Obernier K, Alvarez-Buylla A. 2012. Adult neural stem cells bridge their niche. Cell Stem Cell 10: 698-708.

Garcia-Marques J, Lopez-Mascaraque L. 2013. Clonal identity determines astrocyte cortical heterogeneity. Cereb Cortex 23: 1463-1472.

Ge W-P, Miyawaki A, Gage FH, Jan YN, Jan LY. 2012. Local generation of glia is a major astrocyte source in postnatal cortex. Nature 484: 376-380.

Greig LC, Woodworth MB, Galazo MJ, Padmanabhan H, Macklis JD. 2013. Molecular logic of neocortical projection neuron specification, development and diversity. Nat Rev Neurosci 14: 755-769.

Grove EA, Williams BP, Li DQ, Hajihosseini M, Friedrich A, Price J. 1993. Multiple restricted lineages in the embryonic rat cerebral cortex. Development 117: 553-561.

Guo C, Eckler MJ, McKenna WL, McKinsey GL, Rubenstein JL, Chen B. 2013. Fezf2 expression identifies a multipotent progenitor for neocortical projection neurons, astrocytes, and oligodendrocytes. Neuron 80: 1167-1174.

Hack MA, Saghatelyan A, de Chevigny A, Pfeifer A, AsheryPadan R, Lledo PM, Götz M. 2005. Neuronal fate determinants of adult olfactory bulb neurogenesis. Nat Neurosci 8: $865-872$.

Hochstim C, Deneen B, Lukaszewicz A, Zhou Q, Anderson DJ. 2008. Identification of positionally distinct astrocyte subtypes whose identities are specified by a homeodomain code. Cell 133: 510-522.

Ihrie RA, Shah JK, Harwell CC, Levine JH, Guinto CD, Lezameta M, Kriegstein AR, Alvarez-Buylla A. 2011. Persistent sonic hedgehog signaling in adult brain determines neural stem cell positional identity. Neuron 71: 250-262.

Imayoshi I, Sakamoto M, Ohtsuka T, Takao K, Miyakawa T, Yamaguchi M, Mori K, Ikeda T, Itohara S, Kageyama R. 2008. Roles of continuous neurogenesis in the structural and functional integrity of the adult forebrain. $\mathrm{Nat} \mathrm{Neu}$ rosci 11: 1153-1161.

Imura T, Kornblum HI, Sofroniew MV. 2003. The predominant neural stem cell isolated from postnatal and adult forebrain but not early embryonic forebrain expresses GFAP. J Neurosci 23: 2824-2832.

Isshiki T, Pearson B, Holbrook S, Doe CQ. 2001. Drosophila neuroblasts sequentially express transcription factors 
O.A. Bayraktar et al.

which specify the temporal identity of their neuronal progeny. Cell 106: 511-521.

Jessell TM. 2000. Neuronal specification in the spinal cord: Inductive signals and transcriptional codes. Nat Rev Genet 1: 20-29.

Kaneko N, Marín O, Koike M, Hirota Y, Uchiyama Y, Wu JY, Lu Q, Tessier-Lavigne M, Alvarez-Buylla A, Okano H, et al. 2010. New neurons clear the path of astrocytic processes for their rapid migration in the adult brain. Neuron 67: $213-223$.

Koeberle PD, Bähr M. 2004. Growth and guidance cues for regenerating axons: Where have they gone? J Neurobiol 59: $162-180$.

Kohwi M, Doe CQ. 2013. Temporal fate specification and neural progenitor competence during development. Nat Rev Neurosci 14: 823-838.

Kohwi M, Petryniak MA, Long JE, Ekker M, Obata K, Yanagawa Y, Rubenstein JL, Alvarez-Buylla A. 2007. A subpopulation of olfactory bulb GABAergic interneurons is derived from Emxl - and Dlx5/6-expressing progenitors. J Neurosci 27: 6878-6891.

Kolodkin AL, Levengood DV, Rowe EG, Tai YT, Giger RJ Ginty DD. 1997. Neuropilin is a semaphorin III receptor. Cell 90: 753-762.

Krencik R, Weick JP, Liu Y, Zhang Z-J, Zhang S-C. 2011. Specification of transplantable astroglial subtypes from human pluripotent stem cells. Nat Biotechnol 29: 528 534.

Kriegstein A, Alvarez-Buylla A. 2009. The glial nature of embryonic and adult neural stem cells. Ann Rev Neurosci 32: 149-184.

Laywell ED, Rakic P, Kukekov VG, Holland EC, Steindler DA. 2000. Identification of a multipotent astrocytic stem cell in the immature and adult mouse brain. Proc Natl Acad Sci 97: 13883-13888.

Li X, Erclik T, Bertet C, Chen Z, Voutev R, Venkatesh S, Morante J, Celik A, Desplan C. 2013. Temporal patterning of Drosophila medulla neuroblasts controls neural fates. Nature 498: 456-462.

Lledo P-M, Merkle FT, Alvarez-Buylla A. 2008. Origin and function of olfactory bulb interneuron diversity. Trends Neurosci 31: 392-400.

Luskin MB, McDermott K. 1994. Divergent lineages for oligodendrocytes and astrocytes originating in the neonatal forebrain subventricular zone. Glia 11: 211-226.

Luskin MB, Pearlman AL, Sanes JR. 1988. Cell lineage in the cerebral cortex of the mouse studied in vivo and in vitro with a recombinant retrovirus. Neuron 1: 635-647.

Luskin MB, Parnavelas JG, Barfield JA. 1993. Neurons, astrocytes, and oligodendrocytes of the rat cerebral cortex originate from separate progenitor cells: An ultrastructural analysis of clonally related cells. J Neurosci 13: $1730-1750$.

Magavi S, Friedmann D, Banks G, Stolfi A, Lois C. 2012. Coincident generation of pyramidal neurons and protoplasmic astrocytes in neocortical columns. J Neurosci 32: 4762-4772.

McCarthy M, Turnbull DH, Walsh CA, Fishell G. 2001. Telencephalic neural progenitors appear to be restricted to regional and glial fates before the onset of neurogenesis. J Neurosci 21: 6772-6781.
McConnell SK. 1992. The control of neuronal identity in the developing cerebral cortex. Curr Opin Neurobiol 2: 23-27.

Merkle FT, Tramontin AD, Garcia-Verdugo JM, AlvarezBuylla A. 2004. Radial glia give rise to adult neural stem cells in the subventricular zone. Proc Natl Acad Sci 101: $17528-17532$.

Merkle FT, Mirzadeh Z, Alvarez-Buylla A. 2007. Mosaic organization of neural stem cells in the adult brain. Science 317: 381-384.

Merkle FT, Fuentealba LC, Sanders TA, Magno L, Kessaris N, Alvarez-Buylla A. 2013. Adult neural stem cells in distinct microdomains generate previously unknown interneuron types. Nat Neurosci 17: 207-214.

Miller RH, Raff MC. 1984. Fibrous and protoplasmic astrocytes are biochemically and developmentally distinct. $J$ Neurosci 4: 585-592.

Mirzadeh Z, Merkle FT, Soriano-Navarro M, Garcia-Verdugo JM, Alvarez-Buylla A. 2008. Neural stem cells confer unique pinwheel architecture to the ventricular surface in neurogenic regions of the adult brain. Cell Stem Cell 3: 265-278.

Molofsky AV, Krencik R, Ullian EM, Tsai H-H, Deneen B, Richardson WD, Barres BA, Rowitch DH. 2012. Astrocytes and disease: A neurodevelopmental perspective. Genes Dev 26: 891-907.

Molofsky AV, Kelley KW, Tsai H-H, Redmond SA, Chang SM, Madireddy L, Chan JR, Baranzini SE, Ullian EM, Rowitch DH. 2014. Astrocyte-encoded positional cues maintain sensorimotor circuit integrity. Nature 509: 189-194.

Morshead CM, Garcia AD, Sofroniew MV, van Der Kooy D. 2003. The ablation of glial fibrillary acidic protein-positive cells from the adult central nervous system results in the loss of forebrain neural stem cells but not retinal stem cells. Eur J Neurosci 18: 76-84.

Muroyama Y, Fujiwara Y, Orkin SH, Rowitch DH. 2005. Specification of astrocytes by bHLH protein SCL in a restricted region of the neural tube. Nature 438: 360-363.

Noctor SC, Flint AC, Weissman TA, Wong WS, Clinton BK, Kriegstein AR. 2002. Dividing precursor cells of the embryonic cortical ventricular zone have morphological and molecular characteristics of radial glia. J Neurosci 22: 3161-3173.

Oberheim NA, Wang X, Goldman S, Nedergaard M. 2006. Astrocytic complexity distinguishes the human brain. Trends Neurosci 29: 547-553.

Parnavelas JG. 1999. Glial cell lineages in the rat cerebral cortex. Exp Neurol 156: 418-429.

Parnavelas JG, Barfield JA, Franke E, Luskin MB. 1991. Separate progenitor cells give rise to pyramidal and nonpyramidal neurons in the rat telencephalon. Cereb Cortex 1: 463-468.

Parpura V, Haydon PG, eds. 2008. Astrocytes in (patho)physiology of the nervous system. Springer, New York.

Parras CM, Galli R, Britz O, Soares S, Galichet C, Battiste J, Johnson JE, Nakafuku M, Vescovi A, Guillemot F. 2004 Mash1 specifies neurons and oligodendrocytes in the postnatal brain. EMBO J 23: 4495-4505. 
Pasterkamp RJ, Giger RJ. 2009. Semaphorin function in neural plasticity and disease. Curr Opin Neurobiol 19: 263-274.

Paterson JA, Privat A, Ling EA, Leblond CP. 1973. Investigation of glial cells in semithin sections: III. Transformation of subependymal cells into glial cells, as shown by radioautography after ${ }^{3} \mathrm{H}$-thymidine injection into the lateral ventricle of the brain of young rats. J Comp Neurol 149: $83-102$.

Petit A, Pierret P, Vallée A, Doucet G. 2001. Astrocytes from cerebral cortex or striatum attract adult host serotoninergic axons into intrastriatal ventral mesencephalic cografts. J Neurosci 21: 7182-7193.

Petreanu L, Alvarez-Buylla A. 2002. Maturation and death of adult-born olfactory bulb granule neurons: Role of olfaction. J Neurosci 22: 6106-6113.

Price J, Thurlow L. 1988. Cell lineage in the rat cerebral cortex: A study using retroviral-mediated gene transfer. Development 104: 473-482.

Puelles L, Rubenstein JL. 2003. Forebrain gene expression domains and the evolving prosomeric model. Trends Neurosci 26: 469-476.

Qian X, Shen Q, Goderie SK, He W, Capela A, Davis AA, Temple S. 2000. Timing of CNS cell generation: A programmed sequence of neuron and glial cell production from isolated murine cortical stem cells. Neuron 28: 69-80.

Regan MR, Huang YH, Kim YS, Dykes-Hoberg MI, Jin L, Watkins AM, Bergles DE, Rothstein JD. 2007. Variations in promoter activity reveal a differential expression and physiology of glutamate transporters by glia in the developing and mature CNS. J Neurosci 27: 6607-6619.

Rowitch DH, Kriegstein AR. 2010. Developmental genetics of vertebrate glial-cell specification. Nature 468: 214 222.

Sakamoto M, Ieki N, Miyoshi G, Mochimaru D, Miyachi H, Imura T, Yamaguchi M, Fishell G, Mori K, Kageyama R, et al. 2014. Continuous postnatal neurogenesis contributes to formation of the olfactory bulb neural circuits and flexible olfactory associative learning. J Neurosci 34: $5788-5799$.

Shen Q, Wang Y, Dimos JT, Fasano CA, Phoenix TN, Lemischka IR, Ivanova NB, Stifani S, Morrisey EE, Temple S. 2006. The timing of cortical neurogenesis is encoded within lineages of individual progenitor cells. Nat Neurosci 9: 743-751.

Shen Q, Wang Y, Kokovay E, Lin G, Chuang SM, Goderie SK, Roysam B, Temple S. 2008. Adult SVZ stem cells lie in a vascular niche: A quantitative analysis of niche cell-cell interactions. Cell Stem Cell 3: 289-300.

Shu T, Richards LJ. 2001. Cortical axon guidance by the glial wedge during the development of the corpus callosum. J Neurosci 21: 2749-2758.

Shu T, Sundaresan V, McCarthy MM, Richards LJ. 2003. Slit2 guides both precrossing and postcrossing callosal axons at the midline in vivo. J Neurosci 23: 8176-8184.

Sirko S, Behrendt G, Johansson PA, Tripathi P, Costa M, Bek S, Heinrich C, Tiedt S, Colak D, Dichgans M, et al. 2013. Reactive glia in the injured brain acquire stem cell properties in response to sonic hedgehog. Cell Stem Cell 12: $426-439$.
Stenman J, Toresson H, Campbell K. 2003. Identification of two distinct progenitor populations in the lateral ganglionic eminence: Implications for striatal and olfactory bulb neurogenesis. J Neurosci 23: 167-174.

Sur M, Rubenstein JLR. 2005. Patterning and plasticity of the cerebral cortex. Science 310: 805-810.

Swanson RA, Liu J, Miller JW, Rothstein JD, Farrell K, Stein BA, Longuemare MC. 1997. Neuronal regulation of glutamate transporter subtype expression in astrocytes. J Neurosci 17: 932-940.

Tan SS, Faulkner-Jones B, Breen SJ, Walsh M, Bertram JF, Reese BE. 1995. Cell dispersion patterns in different cortical regions studied with an X-inactivated transgenic marker. Development 121: 1029-1039.

Tavazoie M, Van der Veken L, Silva-Vargas V, Louissaint M, Colonna L, Zaidi B, García-Verdugo JM, Doetsch F. 2008. A specialized vascular niche for adult neural stem cells. Cell Stem Cell 3: 288-379.

Tien A-C, Tsai H-H, Molofsky AV, McMahon M, Foo LC, Kaul A, Dougherty JD, Heintz N, Gutmann DH, Barres BA, et al. 2012. Regulated temporal-spatial astrocyte precursor cell proliferation involves BRAF signalling in mammalian spinal cord. Development 139: 2477-2487.

Tsai H-H, Li H, Fuentealba LC, Molofsky AV, Taveira-Marques R, Zhuang H, Tenney A, Murnen AT, Fancy SPJ, Merkle F, et al. 2012. Regional astrocyte allocation regulates CNS synaptogenesis and repair. Science 337: $358-$ 362 .

Unni DK, Piper M, Moldrich RX, Gobius I, Liu S, Fothergill T, Donahoo A-LS, Baisden JM, Cooper HM, Richards LJ. 2012. Multiple slits regulate the development of midline glial populations and the corpus callosum. Dev Biol 365: 36-49.

Ventura RE, Goldman JE. 2007. Dorsal radial glia generate olfactory bulb interneurons in the postnatal murine brain. J Neurosci 27: 4297-4302.

Wachowiak M, Shipley MT. 2006. Coding and synaptic processing of sensory information in the glomerular layer of the olfactory bulb. Semin Cell Dev Biol 17: 411-423.

Waclaw RR, Wang B, Pei Z, Ehrman LA, Campbell K. 2009. Distinct temporal requirements for the homeobox gene Gs $x 2$ in specifying striatal and olfactory bulb neuronal fates. Neuron 63: 451-465.

Walsh C, Cepko CL. 1988. Clonally related cortical cells show several migration patterns. Science 241: 1342-1345.

Wichterle H, García-Verdugo JM, Herrera DG, AlvarezBulla A. 1999. Young neurons from medial ganglionic eminence disperse in adult and embryonic brain. Nat Neurosci 2: 461-466.

Wonders CP, Anderson SA. 2006. The origin and specification of cortical interneurons. Nat Rev Neurosci 7: 687696.

Wu S, Wu Y, Capecchi MR. 2006. Motoneurons and oligodendrocytes are sequentially generated from neural stem cells but do not appear to share common lineage-restricted progenitors in vivo. Development 133: 581-590.

Yang Y, Vidensky S, Jin L, Jie C, Lorenzini I, Frankl M, Rothstein JD. 2011. Molecular comparison of $\mathrm{GLT}^{+}$ and ALDH1L1 ${ }^{+}$astrocytes in vivo in astroglial reporter mice. Glia 59: 200-207. 
O.A. Bayraktar et al.

Young KM, Fogarty M, Kessaris N, Richardson WD. 2007. Subventricular zone stem cells are heterogeneous with respect to their embryonic origins and neurogenic fates in the adult olfactory bulb. J Neurosci 27: 8286-8296.

Yun K, Garel S, Fischman S, Rubenstein JL. 2003. Patterning of the lateral ganglionic eminence by the Gsh1 and Gsh2 homeobox genes regulates striatal and olfactory bulb histogenesis and the growth of axons through the basal ganglia. J Comp Neurol 461: 151-165.

Zong H, Espinosa JS, Su HH, Muzumdar MD, Luo L. 2005. Mosaic analysis with double markers in mice. Cell 121: 479-492. 


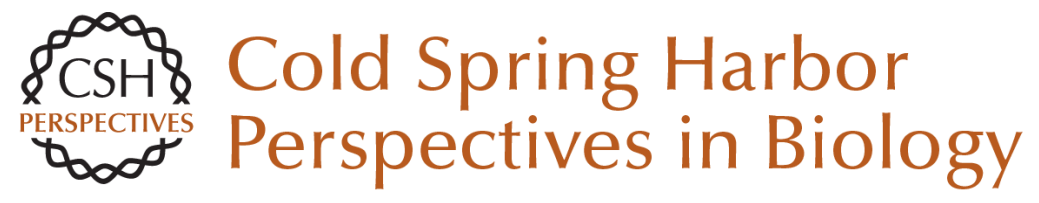

\section{Astrocyte Development and Heterogeneity}

Omer Ali Bayraktar, Luis C. Fuentealba, Arturo Alvarez-Buylla and David H. Rowitch

Cold Spring Harb Perspect Biol 2015; doi: 10.1101/cshperspect.a020362 originally published online November 20, 2014

\section{Subject Collection Glia}

The Nodes of Ranvier: Molecular Assembly and Maintenance

Matthew N. Rasband and Elior Peles

Microglia in Health and Disease

Richard M. Ransohoff and Joseph El Khoury

The Astrocyte: Powerhouse and Recycling Center Bruno Weber and L. Felipe Barros

Microglia Function in Central Nervous System

Development and Plasticity

Dorothy P. Schafer and Beth Stevens

Transcriptional and Epigenetic Regulation of Oligodendrocyte Development and Myelination in the Central Nervous System

Ben Emery and Q. Richard Lu

Origin of Microglia: Current Concepts and Past

Controversies

Florent Ginhoux and Marco Prinz

Glia Disease and Repair--Remyelination

Robin J.M. Franklin and Steven A. Goldman

Astrocytes in Neurodegenerative Disease

Hemali Phatnani and Tom Maniatis
Oligodendrocyte Development and Plasticity Dwight E. Bergles and William D. Richardson

Oligodendrocytes: Myelination and Axonal

Support Mikael Simons and Klaus-Armin Nave

Drosophila Central Nervous System Glia Marc R. Freeman

Perisynaptic Schwann Cells at the Neuromuscular

Synapse: Adaptable, Multitasking Glial Cells Chien-Ping Ko and Richard Robitaille

Astrocytes Control Synapse Formation, Function, and Elimination Won-Suk Chung, Nicola J. Allen and Cagla Eroglu

Schwann Cell Myelination James L. Salzer

Schwann Cells: Development and Role in Nerve Repair

Kristján R. Jessen, Rhona Mirsky and Alison C. Lloyd

Perineurial Glia

Sarah Kucenas

For additional articles in this collection, see http://cshperspectives.cshlp.org/cgi/collection/

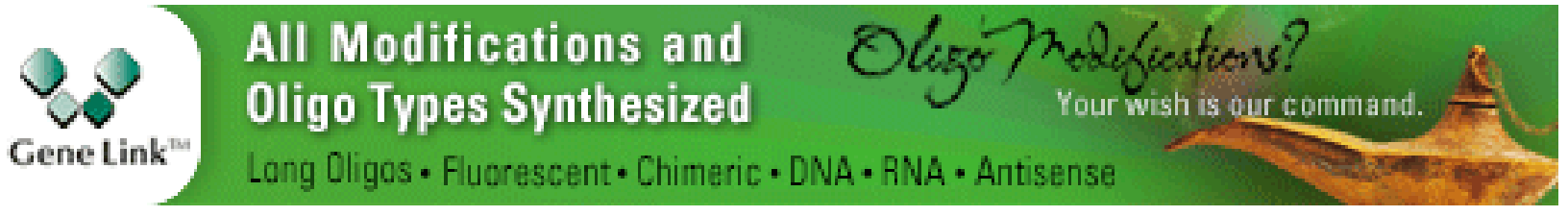

